\title{
O Surgimento da Clínica Psicológica: Da Prática Curativa aos Dispositivos de Promoção da Saúde
}

The Beginning of the Psycological Clinic: From the Healing Practice to the Dispositives to Promote Health

Jacqueline de Oliveira

Moreira,

Roberta Carvalho

Romagnoli \&

Edwiges de Oliveira

Neves

Pontifícia Universidade

Católica de Minas Gerais

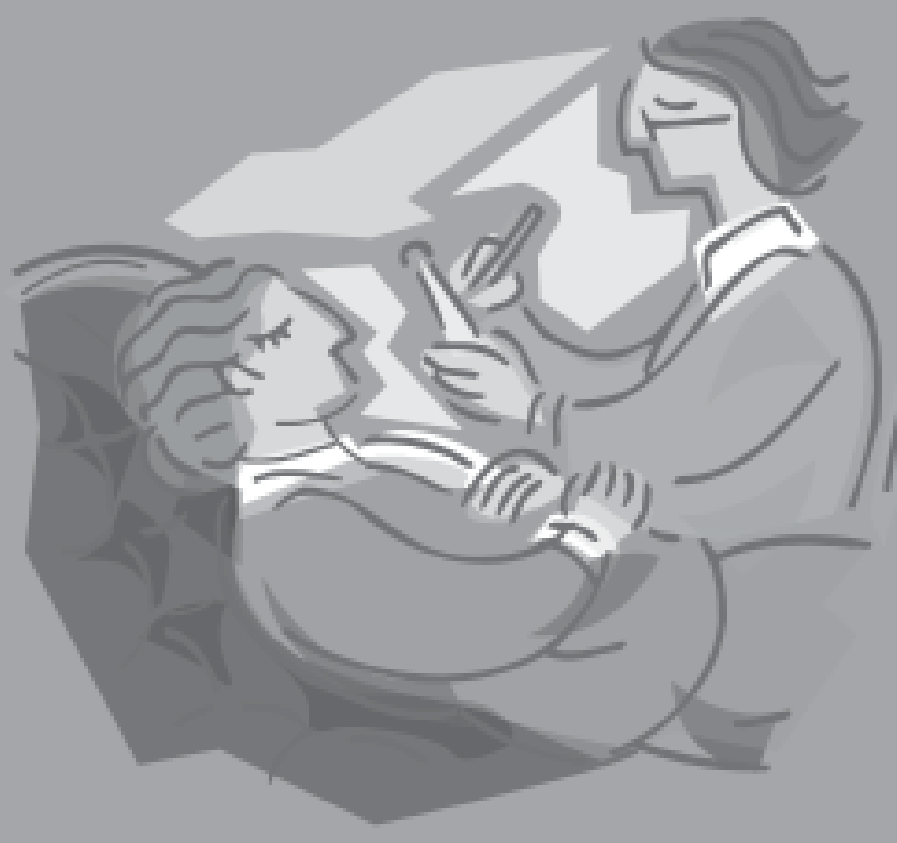




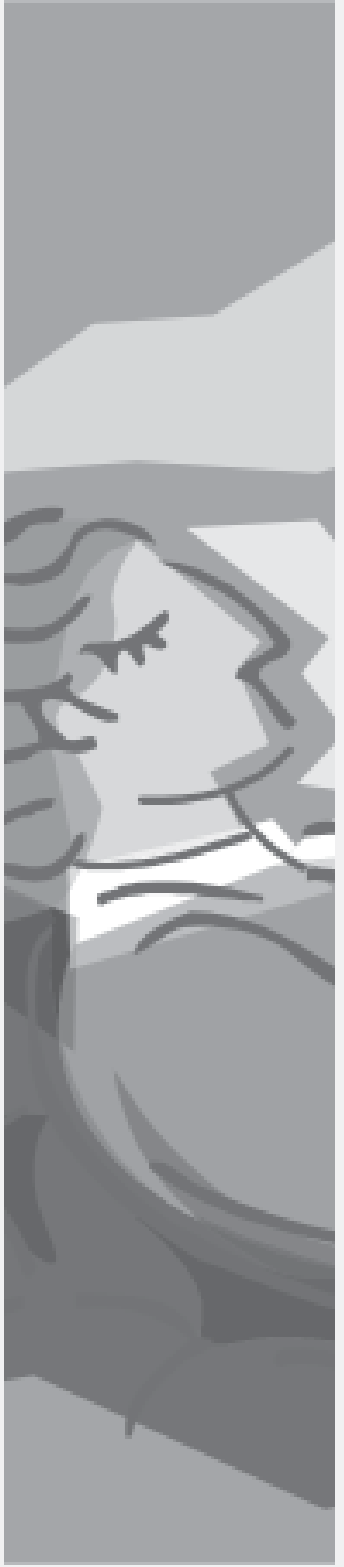

Resumo: O presente artigo pretende trabalhar com o conceito de clínica psicológica e tenta definir esse campo de atuação do psicólogo através de uma análise histórica do surgimento dessa prática e de uma reflexão sobre os limites do modelo de clínica como prática individual de consultório, em contraposição a um modelo de clínica chamada social, que sustenta novas atuações no campo da Psicologia, no Brasil. Assim, iremos, primeiramente, buscar as origens etimológicas, históricas e reflexivas do termo clínica. Em seguida, pretendemos refletir sobre as articulações entre a Psicologia e o individualismo moderno, e, ainda, sobre os limites da clínica entendida como prática liberal, privada e individualizante. Por fim, defenderemos, para além da cisão entre clínica e política, presente no modelo tradicional, uma definição de clínica social como prática ética e política das intervenções, comprometida com a promoção da saúde e engajada na realidade social brasileira.

Palavras-chave: Psicologia clínica, individualismo, escuta, clínica social.

Abstract: This article intends to work with the clinical psychological concept trying to define the psychologist field across a historical analysis of the beginning of this practice and a reflection about the model limits of clinic as an individual practice at the office, in opposite to a model of clinic called social, that supports new performances on the Psychology field in Brazil. First, we will look for the etymological, historical and reflexive origins of the term clinic. Then, we intend to reflect about the articulations between Psychology and the modern individualism and the limits of the clinic understood as a liberal and private practice. In the end, we will defend beyond the division between clinic and politics, in the tradicional model, a definition of social clinic as a political and ethical position of interventions engaged with the promotion of health and with the Brazilian social reality.

Key words: clinical Psychology, individualism, listening, social clinic. 
Conselho Federal de Psicologia, em recente pesquisa (Who, 2001, pp. 7-9), apresentou originariamente, a atividade clínica (do grego klinêleito) é a do médico que, à cabeceira do doente, examina as manifestações da doença para fazer um diagnóstico, um prognóstico e prescrever um tratamento"

Doron e Parot um dado significativo sobre a atuação do psicólogo no Brasil. Entre os psicólogos (75\%) que estavam exercendo a profissão na data da pesquisa, a maioria $(54,9 \%)$ se dedicava à clínica em consultório, e 12,6\% atuava com Psicologia da saúde, sendo que, nesse campo, a prática, na maioria das vezes, também é clínica. Mas, anterior à discussão sobre a atuação do psicólogo, no Brasil, uma questão nos parece prioritária: o que é Psicologia clínica? Dutra (2004) revela que alguns conceitos são pertinentes à prática clínica, como escuta clínica, sofrimento psíquico, subjetividade.

Na trilha de possíveis respostas para a pergunta “o que é clínica?”, iremos, primeiramente, buscar as origens etimológicas, históricas e reflexivas do termo clínica. Em seguida, pretendemos refletir sobre as articulações entre a Psicologia e o individualismo moderno, e ainda sobre os limites da clínica entendida como prática liberal, privada e individualizante. Por fim, para além da cisão entre clínica e política, presente no modelo tradicional, defenderemos uma definição de clínica social como uma prática ética e política de escuta dos sujeitos, comprometida com a promoção da saúde e engajada na realidade social brasileira.

\section{O surgimento da clínica}

Primeiramente, faz-se necessário compreender o significado do termo clínica para, posteriormente, conhecer sua trajetória histórica. Segundo Doron \& Parot (1998), “(...) originariamente, a atividade clínica (do grego klinê - leito) é a do médico que, à cabeceira do doente, examina as manifestações da doença para fazer um diagnóstico, um prognóstico $e$ prescrever um tratamento" (Doron e Parot, 1998, pp.144-145). Para tal, o médico faria uso da observação e da entrevista. Esses procedimentos, inicialmente, já nos suscitam reflexões acerca da influência do saber médico sobre o fazer "psi".

No saber médico que sustenta a prática médica, é impossível diagnosticar sem antes descrever os sintomas/sinais e conhecer os antecedentes da enfermidade. Do mesmo modo, não é possível fazer um prognóstico sem antes obter um diagnóstico. Entretanto, nem sempre foi assim. Antes de Hipócrates, a Medicina estava mais próxima do mágico do que do racional. Ele introduziu uma transformação na Medicina, na Grécia, há 2.500 anos, na tentativa de compreender a história da doença que provoca, no paciente, a necessidade de procurar tratamento.

Hipócrates inaugurou a observação clínica e criou a anamnese, definindo-a como a primeira etapa do exame médico. Aliás, o próprio exame médico foi por ele introduzido na clínica, objetivando a obtenção de dados para a elaboração do diagnóstico e do prognóstico. o exame médico hipocrático consistia em medir a temperatura através da imposição das mãos, observar cuidadosamente, apalpar o corpo e auscultar os batimentos cardíacos, dentre outras ações. Com esses instrumentos - observação, anamnese e exame -, o pai da Medicina foi capaz de descrever mais de quarenta e cinco enfermidades, que prevaleceram até o século XVII.

Já a Medicina romana pouco contribuiu para a clínica médica, embora tenha acrescentado muito aos conhecimentos de anatomia e fisiologia, graças a Galeno. Na era medieval, a Europa estagnou nesse campo de conhecimento. As grandes contribuições, nesse período, foram da Pérsia e dos países árabes. Surge, na Pérsia, um dos maiores nomes da Medicina clínica de todos os tempos: Abu al Hussein ibn Abdallah in Sina, conhecido por Avicena (980-1037 d.C.). Segundo Rezende (2006), o Cânon é a maior obra de Avicena; ela é composta por cinco volumes e contém um grande número de histórias clínicas. Na 
obra citada, encontramos descrições precisas de doenças como hidrofobia, nefrite crônica e outras. Depois da magistral obra de Avicena, a história da Medicina vive uma fase de pequenos avanços no século XVII e no início do século XVIII.

O auge da clínica médica se situa entre o final do século XVIII e o início do século XIX. Esse último foi, sem dúvida, um dos séculos mais prósperos para a área, devido às muitas descobertas no ramo da Biologia e às invenções que possibilitaram a instrumentalização médica. Parece-nos pertinente ressaltar que, segundo Rezende (2006), Foucault introduz uma confusão histórica ao enunciar a origem da clínica no fim do século XVIII e início do XIX. Na verdade, a clínica médica surgiu com Hipócrates. O que ocorre, no período, é um avanço dos recursos técnicos usados nos diagnósticos. Nas palavras do autor:

O filósofo francês Michel Foucault, em seu livro Nascimento da Clínica, considera o fim do século XVIII e o início do XIX como a época em que despontou a clínica médica. Creio que seria mais apropriado falar em crescimento, em lugar de nascimento, pois o método clínico já existia desde Hipócrates. O século XIX foi, sem dúvida, o século em que a clínica médica teve o seu período áureo, enriquecendo a Medicina com numerosas descobertas, fruto de observações cuidadosas e da instrumentalização do médico (Rezende,2006).

Preocupado, nessa fase, em desenvolver um projeto arqueológico que tinha por objetivo efetuar uma análise histórica da constituição dos saberes das ciências humanas, o referido filósofo enfatiza mais as práticas discursivas que fabricam o objeto de estudo da Medicina do que propriamente sua história. Nesse sentido, Foucault (1977) articula o discurso médico, que inaugura e embasa o campo de atuação e de produção científica da disciplina médica dentro de fatores sociais, políticos, econômicos, tecnológicos e pedagógicos, e que evidencia as relações discursivas que "fabricam” a doença e seu tratamento. Dessa maneira, o discurso médico recebe uma ordenação estabelecida pelos critérios de cientificidade e fundamenta as práticas que organizam a Medicina moderna. O corpo torna-se, assim, motivo de controle disciplinar e tecnológico.

Já na fase seguinte, denominada Genealogia do Poder, o filósofo Michel Foucault lança um olhar crítico sobre as relações de poder que emergem associadas ao saber. Essa coexistência de saber e poder faz com que discursos tidos como verdadeiros sejam ditos sobre algo produzido como objeto de saber. Nesse sentido, verdades imutáveis são questionadas e aparecem imbricadas na produção da subjetividade, tendo como função última a monitoração e a ordenação do que escapa à norma. Aliás, nesse raciocínio, a subjetividade é constituída através de práticas, e as relações de poder são processos que incidem sobre os sujeitos e os corpos, o que nos faz pensar sobre os discursos produzidos pela Medicina e suas produções de formas de ser.

De acordo com Foucault (1999), a modernidade - e aí, sim, mais especificamente, o século XIX - instaurou o poder sobre o homem como ser vivo, e, nesse processo, a Medicina teve papel preponderante. Esse poder recebe o nome de biopoder, poder sobre a vida, e pode ser definido como um “(...) poder que se incumbiu tanto do corpo como da vida, ou que se incumbiu, se vocês preferirem, da vida em geral, com o pólo do corpo e o pólo da população”. (Foucault, 1999, p. 302).

Essa forma de poder possui dois eixos, que atuam, respectivamente, sobre o sujeito e sobre a espécie humana: o poder disciplinar e a biopolítica. O poder disciplinar, que incide sobre os indivíduos e os corpos, fundamentase no sistema racional e científico da sociedade moderna. A biopolítica, por sua vez, tem,
"(...) poder que se incumbiu tanto do corpo como da vida, ou que se incumbiu, se vocês preferirem, da vida em geral, com o pólo do corpo e o pólo da população".

Foucault 
como área de atuação, a população, e é auxiliada por mecanismos de regulamentação da natalidade, da mortalidade, das capacidades biológicas e dos efeitos do meio. A relação entre esses dois eixos é de coexistência e a influência mútua. A biopolítica modifica parcialmente o biopoder e utiliza-o. Entretanto, sua tecnologia não suprime a tecnologia disciplinar.

A partir desses dois eixos, que evidenciam a ligação entre saber e poder, emergem os sistemas de vigilância da subjetividade. Esses sistemas de controle social são praticados pela Medicina e também pela Psicologia. Ao estabelecer o estatuto do homem saudável e “normal”, a Medicina paulatinamente vai exercendo um controle disciplinar e cada vez mais tecnológico, através de modelos cada vez mais refinados, com o intuito de ajustar as distintas materialidades que tem a seu cargo, atuando no cotidiano dos sujeitos, normalizando a população e regulando as políticas de saúde através de um arsenal técnico cada vez mais especializado.

Continuando o exame da perspectiva histórica da clínica no século XX, a Medicina alia-se aos conhecimentos acumulados, às novas tecnologias, o que, por sua vez, revoluciona a prática médica. O incremento dos dispositivos diagnósticos, a abundância de tratamentos sofisticados e o elevado nível de especificidade médica conduzem à seguinte premissa: quanto maior a complexidade, maior a necessidade de especializar-se. Aqui, portanto, a clínica médica se perde entre inúmeras fragmentações e ainda delega ao paciente a decisão sobre qual especialista buscar. É como se a clínica estivesse se abstendo do leito, do debruçar-se sobre, uma vez que o paciente, a partir de seu sintoma, avalia a quem deve recorrer. $\mathrm{O}$ acamado passa a depender de um outro que o faça, já que não é mais o médico quem vai até o paciente, mas é este quem vai até o médico.
Nessa perspectiva, cabem as seguintes perguntas: teria ocorrido aqui uma inversão de papéis? Tamanho nível de especialização não teria conduzido a um afastamento da perspectiva humanista que também fundamenta a Medicina? Embora essas reflexões sejam interessantes do ponto de vista da própria clínica, elas não terão lugar neste trabalho, já que não é nosso objetivo discutir os rumos da clínica médica, mas sim, da clínica psicológica, e a trajetória histórica da Medicina aqui realizada serve apenas para contextualização desse objetivo.

Na era vitoriana, ainda não existia a prática de o cliente buscar auxilio psicológico por si; assim, Sigmund Freud, o pai da psicanálise, imprime, na História, algumas inovações. Primordialmente, na clínica psicanalítica, há um deslocamento do saber. Não mais o médico o detém, mas o cliente. Contudo, é um saber inconsciente. Nesse processo, o analista é um mero facilitador, já que, na condução do tratamento, ele apenas aponta o caminho e o paciente não apenas ouve, como se fosse uma prescrição médica, mas elabora e encontra sua verdade no próprio inconsciente. A cena é ocupada, dessa maneira, pelo discurso do paciente, sem o qual não é possível nem mesmo apontar um caminho. Cabe ao analista apenas mobilizar o paciente a prosseguir na busca de sua verdade. Portanto, quem trabalha, verdadeiramente, na análise, é o analisando. É importante fazer uma diferenciação: enquanto a clínica médica aprimora seus métodos diagnósticos, por via da observação e de complexas tecnologias que sustentam múltiplas possibilidades de intervenção na direção da cura orgânica, a clínica freudiana, embora também se debruce sobre o cliente na busca diagnóstica, enfatiza mais a escuta do sofrimento do que a visão do mesmo, e propõe, como método de intervenção, a psicoterapia/análise.

Freud (1905 [1904]) elabora um texto para explicar o método psicoterápico, e, logo no 
início, adverte que muitos médicos consideram a psicoterapia um produto do misticismo moderno, se comparada aos recursos terapêuticos físico-químicos. Em sua grande capacidade argumentativa, ele irá mostrar que a psicoterapia é um recurso bastante familiar aos médicos, tanto porque foi utilizada na Medicina antiga quanto pelo fato de que todos os médicos, mesmo os modernos, utilizam o recurso da psicoterapia através da sugestão de melhora, que se assenta na confiança do cliente no profissional que o trata.

Segundo o autor, uma máxima dos médicos revela que as doenças não são curadas pelo medicamento, mas pelo médico, ou seja, pela personalidade do médico, na medida em que, através dela, ele exerce uma influência psíquica. A psicoterapia que Freud propõe difere, também, da psicoterapia clássica da Medicina, a da sugestão, que é uma sugestão hipnótica, pois o paciente se encontra "hipnotizado" pelo poder e saber do médico. A psicoterapia proposta por Freud difere da sugestão porque não deposita "algo" na e através da relação; pelo contrário, pretende retirar os possíveis significados dos sintomas.

A terapia analítica, em contrapartida, não pretende acrescentar nem introduzir nada de novo, mas antes tirar, trazer algo à tona, e, para esse fim, preocupa-se com a gênese dos sintomas patológicos e com a trama psíquica da idéia patogênica, cuja eliminação é a sua meta (Freud (1905 [1904]), p. 244). Assim, o caminho para atingir a meta não segue a facilidade direta da remoção através da sugestão, da introdução ou da adição de um elemento, mas da subtração, da retirada dos elementos formadores do sintoma.

Para Freud (1905 [1904]), a técnica da sugestão não possibilita a sustentação da posição de cura, pois oculta o entendimento do jogo de forças psíquicas e não permite identificar a resistência. A cura alcançada após o enfrentamento da resistência permanece, ao desvendar o jogo das forças psíquicas implicadas no processo de adoecimento. Nesse sentido, Freud subverte a lógica do tratamento médico, pois, para ele, a resistência é fundamental no processo de cura.

Muitos são os avanços introduzidos por Freud na clínica psicológica, tais como: a mudança do paradigma da observação para o da escuta, a importância da resistência e, em última instância, a perspectiva de tratar o cliente como um sujeito de sua história de adoecimento, e não como mero objeto. No entanto, a clínica psicanalítica freudiana introduz a questão do segredo como força motriz do processo terapêutico; assim, essa clínica se enquadra em moldes individualistas. O paradigma da psicoterapia como espaço do segredo fortalece o imaginário de que a clínica mais efetiva para tratar os sofrimentos psíquicos seja a clínica individual.

\section{Psicoterapia: campo privilegiado da clínica psicológica - individualismo e prática curativa}

A clínica psicológica é herdeira do modelo médico, no qual, como já dissemos, cabe ao profissional observar e compreender para, posteriormente, intervir, isto é, remediar, tratar, curar. Tratava-se, portanto, de uma prática higienista. Dessa maneira, a clínica psicológica esteve, por um bom tempo, distante das questões sociais.

Freud e a psicanálise, segundo Guerra (2002), serão responsáveis pelo deslocamento da prática fundamentada no olhar (sobre o fenômeno) para a prática fundamentada na escuta (do metafenomenal). Assim, a prática clínica psicológica passa a vincular-se a uma demanda do sujeito, e não necessariamente a uma patologia, como no modelo médico. Mas a vinculação da Psicologia ao individualismo não será superada pelo 
freudismo, pois a Psicologia, em sua origem, inclusive a Psicologia clínica, está atrelada a uma perspectiva individualista.

O início do pensamento moderno é marcado pelo surgimento do sujeito e do individualismo, anunciando assim uma nova fonte de problemas que exigem uma nova ciência para pensar sobre eles. Na famosa tese de Dumont (1993), saímos de um modelo holista de sociedade para um modelo individualista. Explicando essa tese, o psicanalista Benilton Bezerra Júnior nos revela:

(...) a consciência dos sujeitos de sociedades

"(...) os ritmos impostos pela produção industrial e pela vida urbana destroem ou transformam os modos de vida e levam ao individualismo, assim como ao isolamento" hierárquicas, fundada num ideário holista, corresponde a uma imagem de si como integrante de uma totalidade, sua identidade sendo vivida como a expressão de sua vinculação ao todo social. Somente nas sociedades igualitárias, baseadas no individualismo como ideologia hegemônica, seria possível para os sujeitos aperceberem-se e, mais do que isto, viverem sua natureza como sendo de indivíduos, isto é, seres singulares, livres, autônomos, dotados de um mundo interno próprio, morada de sua verdadeira identidade. (Bezerra Júnior , 1989, p. 223).

Assim, o sujeito moderno se percebe como um ser singular, um ser que conquistou o direito de exercer sua individualidade de maneira sigilosa, em segredo, de forma a resguardar-se da exposição pública. Não é por acaso que os fenômenos psicológicos, na Grécia antiga, eram deuses (Phobos, Mnemosine, Eros, dentre outros). Esse fato indica a que distância se estava da idéia de intimidade, de algo que se dá no interior e pertence secretamente ao sujeito. A dimensão da interioridade será introduzida no início da Idade Média, a partir da divulgação, pela Igreja Católica, das experiências do indivíduo como ser sexual. Dessa forma, teremos uma intimidade, um segredo, que aponta um indivíduo voltado para suas mazelas sexuais. O cristianismo introduz a possibilidade de perceber a pessoa em sua interioridade, com o intuito de observar e controlar o lado pecaminoso dessa intimidade. Todavia, somente com o pensamento moderno vamos assistir à valorização da categoria sujeito e da experiência de intimidade, de individualidade. Surge, então, a Psicologia, também como espaço de acolhida para esse ser-sujeitoindividual. $\mathrm{O}$ sujeito não tem mais as grandes estruturas holistas que organizam e oferecem sentido a sua existência; cada um tem que construir por si seus sentidos subjetivos e individuais. Assim, a clínica do segredo cresce e floresce na modernidade.

As mudanças introduzidas pela revolução industrial na produção de bens influenciaram profundamente a sociedade e os indivíduos. Segundo Laville \& Dionne (1999), “(...) os ritmos impostos pela produção industrial e pela vida urbana destroem ou transformam os modos de vida e levam ao individualismo, assim como ao isolamento" (p. 53). Além disso, a distância entre a classe detentora dos meios de produção e o proletariado aumentava cada vez mais. Aqueles que poderiam tirar proveito dessas mudanças “(...) gostariam de propiciar que a nova ordem se estabelecesse sem confrontos" (Laville \& Dionne, 1999, pp. 5354). Surgem, então, as ciências humanas, “(...) com o objetivo de compreender e intervir na ordem social da mesma forma que as ciências naturais tentavam dominar a natureza" (Laville \& Dionne, 1999, pp. 53-54).

Portanto, o surgimento das ciências humanas, inclusive o da Psicologia, esteve ligado aos interesses da nova detentora dos poderes político, econômico e social: a burguesia. Segundo Guerra (2002), “(...) a história da Psicologia nos evidencia uma tradição de trabalho associada ao controle, à higienização e à diferenciação, que, desde os primórdios de seu nascimento, associaram às práticas sociais e políticas a manutenção do status quo” (p. 29). A prática clínica era, portanto, descomprometida com o contexto social, ou, 
ao contrário, comprometida com apenas parte dele.

Tendo sido o surgimento das ciências humanas vinculado aos interesses da classe dominante e estando a própria Psicologia aliada a práticas higienistas, fica evidente que o público de sua intervenção era aquele que não se enquadrava no projeto cartesiano do homem racional, e que uma de suas tarefas era sustentar e manter o individualismo. Dessa maneira, a terapia da alma se inspiraria no modelo da terapia do corpo, isto é, no modelo médico, a fim de ser reconhecida como ciência. Assim, a psicoterapia se tornou um campo privilegiado da clínica psicológica: ela seria, até então, a terapêutica mais adequada para tratar das "mazelas humanas" em que outras tentativas haviam falhado. Os "problemas psicológicos”, uma vez que são imateriais, só se apresentariam através da fala, sobre a qual o psicólogo se “debruçaria” a fim de traçar uma linha de tratamento (diagnóstico, prescrição e prognóstico).

Mas a relação entre a Psicologia e o individualismo é marcada por uma ambigüidade: se, por um lado, o individualismo foi condição sine qua non para o surgimento da Psicologia como ciência, por outro, ele tomará uma forma tal que denunciará a necessidade de que essa mesma Psicologia reflita sobre seus efeitos, o que mudará completamente a relação entre ambos.

Assim, seria possível dar conta de todo tipo de “mazela”, nesse modelo? No nosso entender, não se pode tratar a psique da mesma maneira que se trata do soma e tampouco manter a neutralidade científica diante de um objeto que coincide com o observador. A clínica individual é fundamental, mas não podemos nos perder no individualismo. Não se pode esquecer que a ciência expressa e alimenta ideologias; assim, a idéia de clínica neoliberal alimenta o modelo individualista, por vezes perverso, que se esquece do homem para manter a lógica do capital. Acreditamos que existam outras intervenções psicológicas, de efeitos terapêuticos, resultantes de uma escuta clínica. Como breve exemplo das limitações da clínica quanto ao segredo individual, queremos relatar um episódio referente à prática de uma psicóloga em um hospital público. A psicóloga, novata, interroga a coordenação de psicologia do hospital sobre a possibilidade de se oferecerem mais consultórios dentro do hospital para estagiários atenderem os pacientes. A coordenadora pergunta por que não atender as pessoas no leito, pois atender só aqueles que têm condições médicas de caminhar até o consultório seria excluir os acamados. A psicóloga responde que não pode atender nas enfermarias, porque sempre existe um segredo a ser dito. No nosso entender, manter esse pressuposto é retirar, de alguns sujeitos, a possibilidade de acolhimento, de escuta do sofrimento e até de uma nova posição subjetiva frente ao sofrimento.

Dessa forma, o contexto social passou a adentrar os consultórios de forma a convocar os psicólogos a saírem dele, ou seja, para responder às novas formas de subjetivação e de adoecimento psíquico, o psicólogo deveria compreender a realidade local. A Psicologia “tradicional” é “obrigada” a se redesenhar, tornando-se mais crítica e engajada socialmente.

Segundo Moreira (2004), é fácil compreender a tentação individualista, pois o processo de constituição da subjetividade só é possível mediante o encontro intersubjetivo; é o outro que possibilita ao eu o ingresso no mundo social. No entanto, o eu vive, primeiramente, um momento de "não-eu”, de uma consciência em si, sem auto-reflexão, para usar a expressão de Lévinas (1983,1997), uma “consciência-nãointencional”. Em sua não-intencionalidade, anterior a todo querer e a qualquer falta, a identidade da "consciência não-intencional" encontra-se exposta, entregue à exterioridade absolutamente estranha e imprevisível. 
Segundo Lévinas (1983, 1997), a consciência, antes de significar um saber de si, é apagamento ou discrição da presença, sem intenção, sem nome, sem situação, sem títulos, sem visada e sem a proteção da máscara protetora do eu. No entanto, quando essa consciência se torna intencional, quando alcança o estatuto de uma consciência-de-si, pensa que esse é o ponto zero. A consciência só reconhece como momento inaugural aquele em que ela possui racionalidade; portanto, é facilmente capturada pelo engodo de pensar que o eu é anterior ao outro. $\mathrm{Na}$ modalidade voluntária da consciência intencional, sua atividade é mortífera em relação à dimensão do outro. No domínio da consciência, o outro é visado para completar. $\mathrm{O}$ eu prefigurado pela consciência intencional conhece e representa, e, nesse processo, conhece a si mesmo refletido na realidade objetiva que ele próprio constitui. Assim, a falácia individualista é facilmente compreendida; o eu, em sua arrogância, crê que é anterior ao outro. De acordo como Moreira (2004), do ponto de vista lógico, o eu é anterior ao outro, pois só pode haver a distinção de fronteiras quando os dois elementos têm claros, racionalmente delimitados, seus limites. Mas, do ponto de vista ontológico, o outro é anterior ao eu. Todavia, a consciência-não-intencional não possui instrumentos racionais para apreender esse momento de dependência do outro.

Moreira (2004) defende a tese de que esse ponto pode ser um fundamento, uma perspectiva para a Psicologia engajada no compromisso social. A Psicologia não teria, como tarefa, fortalecer a arrogância do eu igual a eu, nos projetos de busca do "verdadeiro eu”, mas desvelar, para o eu, sua pertinência necessária e vital no campo do outro, revelar sua condição estruturante de "ser com”. O sujeito percorreria o trajeto de uma consciência-em-si, que se desconhece, para uma consciência-para-si, que pode se precipitar nas águas do arrogante individualismo. O projeto da Psicologia como compromisso social anuncia a dimensão da consciência-para-si e para-o-outro, sendo que a condição de ser para outro é anterior à consciência de si.

A Psicologia, ou melhor, as psicologias, devem encontrar seu compromisso social, pois o eu não se constitui sem o outro, ou seja, não há individualismo que se sustente na ausência do social. Se o paradigma moderno é o da consciência que propicia o individualismo, o paradigma contemporâneo é o da linguagem que pressupõe o encontro intersubjetivo. $\mathrm{O}$ “paradigma da linguagem” apenas demarca o campo das teorias que concebem o sujeito originariamente como "ser social”, "ser-nomundo”, "ser comunicacional”, “ser-com”, enfim, mergulhado no universo das interações simbólicas.

\section{As novas modalidades de clínica para além da psicoterapia: clínica social e promoção da saúde}

Desde o final do século passado e ainda no início deste século, presenciamos, no País, um aumento considerável das áreas de atuação da Psicologia, o que evidencia uma ampliação paulatina de seus locais de trabalho: o psicólogo torna-se presença cada vez mais constante nos sistemas de saúde pública, nos centros de reabilitação, nos asilos, nos hospitais psiquiátricos e gerais, no sistema judiciário, nas creches, nas penitenciárias, nas comunidades. Dessa maneira, surgem, para o profissional, outras oportunidades de trabalho que escapam a seus espaços usuais de atuação, restritos até então aos consultórios, às escolas e às empresas.

Todavia, cabe ressaltar que o psicólogo se depara, portanto, com o desafio de trilhar novos caminhos e de sustentar suas conquistas recentes. Esse desafio pressupõe, de acordo com Romagnoli (2006/no prelo), não só a 
disseminação da especialidade do psicólogo para um número maior de pessoas e de classes sociais mas também a produção de novos recursos em sua formação e de novas formas de exercício profissional, que apostem na construção de práticas ético-políticas.

Nesse sentido, concordamos com Figueiredo (1996) quando ele afirma que a clínica psicológica se caracteriza não pelo local em que se realiza - o consultório -, mas pela qualidade da escuta e da acolhida que se oferece ao sujeito: a escuta e a acolhida do excluído do discurso. Portanto, ser psicólogo clínico implica determinada postura diante do outro. Nesse sentido, podemos fazer a seguinte observação:

Assim, não importa em que lugar ou espaço o ato clínico aconteça, seja no âmbito privado ou público, numa relação diádica, grupal ou coletiva. Este será sempre um fazer psicológico que se pautará em concepções teóricas e metodológicas que refletirão essa postura diante do sofrimento ou fenômeno psicológico que se coloca diante dele. Melhor dizendo, o ato clínico se pautará muito mais por uma ética do que por referenciais teóricos fechados. (Dutra, 2004, s/p).

É claro que essa postura implica se haver com as mudanças provocadas pela relação que ali se trava, relação essa que reflete/remete às outras relações que seus elementos (terapeuta e cliente) possuem fora do setting terapêutico, seja ele qual for. No espaço clínico, estamos em contato com modos de subjetivação que buscam, de alguma maneira, criar alternativas de retificação. Isso significa que o fazer clínico é, também, um fazer político, uma vez que ele é transformador. Segundo Gondar (2006), “(...) mesmo quando [as questões] surgem no seio de uma família, numa escola ou numa relação amorosa, trata-se sempre do quanto $e$ de como o desejo pode produzir e se expressar diante das injunções de assujeitamento" (s/p). Nessa perspectiva, operar mudanças é sempre um fazer político.
Embora, em nosso entender, essa relação seja intrínseca, presenciamos ainda, na forma dominante da prática clínica, o perpetuamento da cisão entre clínica e política. Realizando uma reflexão acerca da relação entre o momento contemporâneo, o exercício da clínica e a produção da subjetividade, Benevides de Barros \& Passos (2004) insistem na articulação desse tripé com o viés político e com a necessidade de uma análise das formas instituídas da clínica. Para tal, os autores examinam as formas de poder da atualidade, que gerenciam a vida e moldam formas de existência, como nos propõem as análises foucaultianas, apontadas no início deste texto. Em plena era da globalização, as subjetividades são geridas por controles parciais e instáveis, que se exercem em redes, que estão em todos os lugares na ordem do dia, e que administram as formas de vida e seu cotidiano. Vale lembrar que esse poder é positivo, direcionado para o consumo e para a serialização, e administra maneiras de ser e de viver.

Frente a essa captura contemporânea da subjetividade, a clínica aflora como possibilidade também de produção, e não somente de reprodução; uma forma de resistência, conforme pontua Romagnoli (2006/no prelo). Nesse espaço, vamos nos deparar com modos de produção, de subjetivação e de construção, formas de se criar a si mesmo e o mundo, que também incidem no espaço social. Nesse contexto, é necessário que os profissionais que atuam nessa área reflitam acerca dos desdobramentos de suas práticas no campo social. Nem que seja através dos sintomas de seus clientes que adentram os consultórios, mantidos e sustentados pelo momento contemporâneo, o social se faz presente e se faz notar nas mudanças que emergem nesse cenário, criando focos enunciativos frente à padronização das subjetividades.

Mediante essas idéias, acreditamos que o estado de potência da vida, inerente à
"(...) mesmo quando [as questões] surgem no seio de uma família, numa escola ou numa relação amorosa, trata-se sempre do quanto e de como o desejo pode produzir e se expressar diante das injunções de assujeitamento"

$(s / P)$ 
subjetividade, pode atualizar-se na experiência clínica e pode atuar como dispositivo para sustentação de modos de existência que se criam, de maneira singular, e que emergem como resistência à reprodução, à massificação, à gerência da vida. Na verdade, a Psicologia se dedica à subjetividade em suas mais variadas aparições, mas devemos pensar não somente no sujeito individual, pois este sempre é fruto de um encontro social. Para tal, é preciso tomar a clínica como plano de produção do coletivo, como sustentação da alteridade: clínica social.

Ao examinar o uso da expressão clínica social, mediante uma perspectiva histórica, Ferreira Neto (2003) afirma que seu uso se inicia, em nosso país, na década de 80 , em associação a uma série de transformações, não só nessa área, mas na Psicologia como um todo. Embora, desde a década de 70 , já houvesse, no Brasil, práticas e grupos "psi” engajados em práticas sociais e com reflexões políticas acerca do que faziam, é necessário frisar que essa postura não atingia o campo da clínica, que se apresentava, de maneira geral, apolítica e distante das questões sociais. Em 1984, com a abertura política, inicia-se o questionamento da neutralidade da clínica, através da ampliação do conceito de política e da constatação da força dos movimentos sociais. Essas alterações confrontam a idéia dominante na prática clínica, até então definida como atividade liberal e privada, que se desenvolvia junto às classes médias e altas.

Em pesquisa efetuada nessa mesma época, com o intuito de conhecer os campos emergentes de exercício dos psicólogos, o Conselho Federal de Psicologia (1988) denuncia a clínica tradicional como prática hegemônica e centrada no indivíduo. De acordo com o órgão, essa atividade tem objetivos analíticos, psicoterapêuticos e/ou psicodiagnósticos, e baseia-se em uma concepção da clínica como um saber/fazer universalizado, associado a uma concepção de sujeito universal e a-histórico, metas e fundamentos que, sem dúvida, circunscrevem a clínica como espaço de reprodução e mantêm a cisão entre clínica e política.

Ainda analisando essa forma dominante, Ferreira Neto (2004), em sua reflexão sobre a formação do psicólogo brasileiro, afirma que outras pesquisas também anunciaram que a visão da prática psicológica como clínica dentro do modelo liberal privado predomina entre os estudantes e profissionais da Psicologia. Em sua pesquisa, o autor pretende investigar o processo de mudança desse privilegiado ideal para a construção de uma clínica social. Concordamos com o autor no que se refere ao esgotamento da clínica liberal curativa dentro de um cenário nacional em que os problemas sociais se multiplicam. Também estamos de acordo com o deslocamento do paradigma da clínica liberal curativa para uma clínica implicada e aplicada nos processos de promoção da saúde no social.

A clínica social nasce como prática que se pretende realizar de forma ampla, envolvida com a construção de novas formas de atuação. A partir da década de 80, como vimos acima, os profissionais "psi" passam a atender a uma clientela oriunda das classes populares em que é inevitável a dimensão social, que, por sua vez, convoca a necessidade de outra escuta e de outra intervenção. Todavia, cabe ressaltar que esse tipo de atividade, por si só, não garante uma prática política e de resistência. A ênfase no social, em seu surgimento, também era despolitizada, e, como se dedicava às camadas baixas da população, consistia, de maneira geral, em práticas assistencialistas. Com o intuito de ocupar novos espaços e realizar práticas diversas, os psicólogos geralmente utilizavam os mesmos modelos do consultório privado. Assim, entendemos que, naquele momento histórico, foi fundamental essa inserção - que, contudo, por si só, não garante novas atuações. 
Atualmente, com as práticas emergentes em Psicologia já solidificadas, percebemos uma flexibilização e uma politização cada vez mais crescentes, que se associam ao desenvolvimento do trabalho clínico. Essa conduta emerge como necessária frente à multideterminação de fatores que atravessam o exercício profissional na diversidade de campos em que o psicólogo se insere. Entretanto, vale lembrar que, quanto mais espaços esse profissional ocupa, mais necessária se torna a realização de análises críticas acerca do poder de suas intervenções e da gerência ou não da vida, em prol da reprodução ou da invenção, isso porque um trabalho com o social não é, por si só, uma prática ética e libertária.

Na verdade, não podemos nos esquecer de que, ultrapassando a homogeneidade e a segurança de nossas especializações, encontramos um mundo portador de facetas variadas. Dinâmico e aberto, esse mundo não se esgota nem se finaliza em nenhuma abordagem; pelo contrário, traduz-se em diversidades e multiplicidades. Analisando essa proposição, Baremblitt (1988) demonstra que o campo de atuação dos trabalhadores na saúde é um espaço de múltiplas determinações, que configuram linhas de força e materialidades bastante diferentes entre si, que podem e devem ser consideradas.

Ao centrar sua proposta somente no manejo de classes sociais distintas, em diferentes espaços de trabalho, o psicólogo corre o risco de nada mais realizar a não ser a adaptação maciça de seus clientes ao mercado globalizado e de distanciar-se da inventividade. Essa diversificação de usuários de seus serviços e esse aumento da demanda de sua atuação profissional não garantem nenhum avanço, apenas respondem a um movimento de psicologização dos problemas da vida e podem aperfeiçoar os mecanismos de exclusão do capitalismo, se o ponto de partida for o de sujeição a uma prática clínica descontextualizada, inquestionável e entendida como verdade.

Tendo como sustentáculo as idéias discutidas acima, ressaltamos que a clínica social não se refere somente ao atendimento das camadas pobres da população nem diz respeito apenas aos novos espaços de atuação em que os psicólogos estão se inserindo. É, antes de tudo, a clínica de qualquer lugar, de qualquer público, que insiste em combater a massificação, cada vez mais presente, e buscar cada vez mais a invenção, na singularidade de cada cliente, na particularidade de cada inserção profissional.

Propomos, portanto, um trabalho de intervenção psicológica, seja qual for a vertente teórica escolhida pelo profissional, que associe o sujeito psicológico ao sujeito político, pois acreditamos que, devido ao alto nível de subjetivismo, de atomização, de narcisismo, um trabalho que possa alcançar algum sucesso deve partir das mazelas íntimas desse sujeito para depois lançá-lo ao campo político, transformando-o em um sujeito histórico, no sentido de se envolver com sua história, com a comunidade, com a humanidade. As produções dominantes no campo da Psicologia ainda enfatizam a formação especializada e tecnicista e perseguem homogeneizações e seguranças ilusórias perante a multideterminação da realidade.

Em nosso entendimento, essa grande ênfase na formação de especialistas traz, como conseqüência imediata, a cisão entre conhecimento e engajamento social. Acreditamos que a articulação do uso de nossa formação acadêmica e de seus efeitos no campo social, mediante o desenvolvimento de um conhecimento crítico de nossas práticas, seja indispensável, sobretudo nesse momento em que outros espaços de atuação foram conquistados e já se encontram sedimentados. No nosso entender, somente sustentando essa problemática é possível promover ações que, 
mesmo parciais, nos conduzam a outras práticas clínicas e sociais.

Por fim, gostaríamos de revelar que muitos profissionais entendem a clínica psicológica como prática liberal que acontece apenas no consultório particular, atrelada ao modelo individualizante. De outro lado, alguns profissionais que defendem uma politização da prática psicológica também são prisioneiros dessa forma de conceituação, e propõem, assim, uma polarização entre intervenção clínica e intervenção psicossocial. Faz-se necessário compreender que a escuta clínica é uma postura ética e política diante do sujeito humano. Não é o local que define a clínica, e sim, a posição do profissional e os objetivos de libertação e potencialização dos sujeitos. 


Jacqueline de Oliveira Moreira
Doutora em Psicologia clínica pela PUC/SP, Mestre em Filosofia pela UFMG,
professora do Mestrado da PUC/MG, psicóloga clínica ? $\begin{array}{r}\text { Roberta Carvalho Romagnoli } \\ \text { Doutora em Psicologia clínica pela PUC/SP, Mestre em Psicologia social pela UFMG, } \\ \text { professora do Mestrado da PUC/MG, psicóloga clínica } \\ \text { Edwiges de Oliveira Neves } \\ \text { Discente do Curso de Psicologia da PUC/MG - Unidade de Betim } \\ \text { Rua Congonhas, 161 - São Pedro Belo Horizonte - MG. CEP - 30.330-100 } \\ \text { E-mail:jackdrawin@yahoo.com.br }\end{array}$

BAREMBLITT, G. Sobre Psicoterapia en las Instituciones y la Institución de la Psicoterapia. In: Saber, Poder, Quehacer y

Deseo. Buenos Aires: Ediciones Nueva Visión, 1988, pp. 13-30.

BENEVIDES DE BARROS, R. D.; PASSOS, E. Clínica, política e as modulações do capitalismo. Lugar Comum, Rio de Janeiro, n. 19-20, pp. 159-71, 2004.

BEZERRA JÚNIOR, B. Subjetividade Moderna e o Campo da Psicanálise. Freud - 50 Anos depois. Rio de Janeiro: Relume Dumará, 1989, pp. 219-239.

CONSELHO FEDERAL DE PSICOLOGIA. Quem É o Psicólogo Brasileiro? São Paulo: Edicon, 1988.

DORON, R.; PAROT, F. (orgs.) Psicologia Clínica. Dicionário de Psicologia. Vol. I. São Paulo: Ática, 1998, pp. 144-145.

DUMONT, L. Ensaios sobre o Individualismo, uma Perspectiva Antropológica Moderna. Rio de Janeiro: Rocco, 1993.

DUTRA, E. Considerações sobre as significações da Psicologia clínica na contemporaneidade. Estudos em Psicologia, v. 9, n. 2, pp. 381387, 2004.

FERREIRA NETO, J. L. Qual éo social da clínica? Uma problematização. Pulsional: Revista de Psicanálise, v. 167, n. 1, pp. 57-65,2003.

A Formação do Psicólogo: Clínica Social e Mercado. São Paulo/Belo Horizonte: Escuta/FUMEC/FCH, 2004.

FIGUEIREDO, L. C. Revisitando as Psicologias: da Epistemologia à Ética das Práticas e Discursos Psicológicos. São Paulo/Petrópolis: EDUC/Vozes, 1996.

FOUCAULT, M. Aula de 17 de março de 1976. In: Em Defesa da Sociedade. Curso no Collège de France (1975-1976). São Paulo: Martins Fontes, 1999, pp. 285-319.

. O Nascimento da Clínica. Rio de Janeiro: Forense Universitária, 1977.
FREUD, S. Sobre a Psicoterapia. (1905 [1904]). In: Freud, S. Um caso de histeria. Três ensaios sobre a sexualidade e outros trabalhos. Edição Standard das Obras Psicológicas Completas de Sigmund Freud, vol. VII. Rio de Janeiro: Imago, 1996, pp. 239-251.

GUERRA, A. M. C. O Social na Clínica e a Clínica do Social: Sutilezas de uma Prática. In: Gonçalves, B. D.; Guerra, A. M. C. \& Moreira, J. de O. (orgs.). Clínica e Inclusão Social: Novos Arranjos Subjetivos e Novas Formas de Intervenção. Belo Horizonte: Edições do Campo Social, 2002, pp. 29-48.

GONDAR, J. A clínica como prática política. Disponível em: <http:/ / www.estadosgerais.org/mundial_rj/download/ 5c_Gondar_147161003_port.pdf\#search='palavra\%20clinica>'. Acesso em abr. de 2006.

LAVILLE, C.; DIONNE, J. A Construção do Saber: Manual de Metodologia de Pesquisa em Ciências Humanas. Porto Alegre: Artes Médicas Sul, 1999.

LÉVINAS, E. A Consciência Não-intencional. In:___ _ Entre Nós: Ensaios sobre a Alteridade. Petrópolis: Vozes, 1997, pp. 165177.

REZENDE, J. M. Caminhos da Medicina: trajetória histórica da clínica médica e suas perspectivas. Palestra na Jornada de Clínica Médica para estudantes de Medicina realizada em Goiânia em 19/ 08/1998. Disponível em: <http://usuarios.cultura.com.br/ jmrezende>. Acesso em abril de 2006.

MOREIRA, J. de O. Material didático aula 1: Psicologia: uma ciência do século XXI. Betim: PUC Minas, 2004. (Mimeografado).

ROMAGNOLI, R. C. Algumas reflexões acerca da clínica social. Revista do Departamento de Psicologia da UFF, Niterói, v. 18, n. 2, jul./dez. 2006 (no prelo).

WHO. Relatório final da pesquisa junto aos associados do Conselho Federal de Psicologia. Brasilia: CFP, 2001. (Mimeografado). 